\title{
Identifikasi Lokasi Perairan Untuk Pengembangan Budidaya Laut di Kabupaten Lombok Utara
}

\author{
Muhammad Junaidi ${ }^{1, *)}$, Nurliah ${ }^{1)}$, Muhammad. Marzuki ${ }^{1)}$, \\ Nunik Cokrowati ${ }^{1)}$, Ibadur Rahman ${ }^{1)}$ \\ 1) Program Studi Budidaya Perairan Universitas Mataram \\ *email: junaidi_md@yahoo.co.id
}

Diterima: 13 Maret 2018 Publish: 28 Juni 2018

Abstrak

\begin{abstract}
Penelitian ini bertujuan mengidentifikasi lokasi perairan untuk pengembangan budidaya laut di Kabupaten Lombok Utara. Pengumpulan data kondisi biofisik perairan yang mencakup aspek kualitas perairan dan oseanografi yang merupakan data penunjang bagi pengambilan keputusan kesesuaian biofisik pengembangan budidaya laut.Identifikasi lokasi perairan untuk budidaya laut menuntut penerapan beberapakriteria. Penerapan kriteria sangat membantu dalam mengidentifikasi dan memilihlokasi budidaya secara obyektif, dimana secara mendasar terdiri dari atas kelompok kriteria kesesuaian kualitas air dan oseanografi. Hasil identifikasi lokasi perairan berdasarkan aspek oseanografi dan kualitas perairan, maka perairan Kabupaten Lombok Utara terutama di Kecamatan Tanjung dan Gangga sangat sesuai untuk pengembangan budidaya laut, terutama komoditas yang memiliki peluang ekspor tinggi seperti kerapu, rumput laut dan kerang mutiara.
\end{abstract}

Kata kunci : identifikasi, lokasi perairan, budidaya laut, pengembangan

\begin{abstract}
Abtract
This study aimed to identify the location of the waters for mariculture development in North Lombok regency.The data collection biophysical conditions of waters which includes aspects of water quality and oceanographic constitute supporting data for decision making biophysical suitability of mariculture development.Identify the location of the waters for mariculture requires the application of several criteria.The application of the criteria is very helpful in identifying and selecting the location of cultivation in an objective, which is basically composed of the top group suitability criteria for water quality and oceanographic. Results of identifying the location of water based on aspects of oceanography and water quality, the waters of the North Lombok, especially in the district of the Tanjung and the Ganga is very suitable for the development of marine aquaculture, especially commodities which have high export opportunities such as grouper, seaweed and pearl shells.
\end{abstract}

Keywords: identification, location waters, aquaculture, development 


\section{Pendahuluan}

Kabupaten Lombok Utara (KLU) merupakan salah satu kabupaten pesisir yang ada di Indonesia, dengan panjang garis pantai sekitar $125 \mathrm{~km}$. Wilayah pesisir dan laut KLU memiliki banyak teluk kecil yang merupakan kawasan potensi untuk pengembangan budidaya laut (marikultur). Menurut Utojo et al. (2000), pengembangan usaha marikultur dapat dilakukan pada kawasan pesisir seperti teluk karena dapat terlindung dari pengaruh arus yang kuat, gelombang yang besar, angin yang kencang serta bebas pencemaran. Marikultur mempunyai prospek yang cerah untuk dikembangkan dalam rangka meningkatkan pendapatan masyarakat pesisir, menambah pendapatan asli daerah (PAD), meningkatkan devisi negara dan menghindari kerusakan lingkungan (Effendi, 2004; Idris et al., 2007). Pengembangan marikultur pada beberapa lokasi pesisir di Pulau Lombok seperti di pesisir Lombok Timur menjadi instrumen peningkatan pendapatan nelayan kecil dan solusi konservasi ekosistem pesisir seperti ekosistem padang lamun (Syukur et al., 2016).
Kerang mutiara, rumput laut, lobster dan kerapu termasuk komoditas perikanan laut yang mempunyai peranan penting sebagai komoditas ekspor, dan keempat komoditas ini telah dikembangkan di Kabupaten Lombok Utara walaupun masih dalam skala kecil dan sederhana.Permintaan dan harga komoditas tersebut di pasar domestik dan internasional terus meningkat setiap tahun.. Hal ini menunjukkan bahwa pengembangan marikultur merupakan solusi yang tepat untuk mengurangi kerusakan ekosistem terumbu karang akibat penangkapan ikan yang tidak bertanggungjawab yang akhir-akhir sering terjadi di KLU.

Marikultur adalah sistem budidaya perairan berbasis air laut (marine base aquaculture), dilakukan pada badan air sehingga bersifat terbuka (Effendi, 2004). Interaksi antara biota kultur dengan lingkungan luar sangat kuat dan hampir tidak ada pembatas. Oleh karena itu, pemilihan lokasi yang tepat dan baik merupakan salah satu faktor penentu keberhasilan usaha marikultur disamping ketersedian benih, pakan serta terjaminnya pasar dan harga (Affan, 
2011). Namun demikian, permasalahan yang terjadi di lapangan adalah penempatan lokasi marikultur masih bersifat preditif sehingga sangat memerlukan suatu gambaran lokasi yang tepat dan terhindar dari pengaruh lingkungan yang tidak mendukung (Radiarta et al., 2005; Ismail et al., 2001). Oleh karena itu, dilakukan penelitian dengan tujuan untuk mengidentifikasi lokasi perairan untuk pengembangan budidaya laut di Kabupaten Lombok Utara.

\section{Bahan dan Metode}

Penelitian dilakukan pada bulan Juni - Oktober 2016 di perairan KLU, dengan menggunakan metoda penelitian survei. Pengumpulan data kondisi biofisik perairan yang mencakup aspek kualitas perairan (fisika, kimia dan biologi) serta oseanografi yang merupakan data penunjang bagi pengambilan keputusan kesesuaian biofisik pengembangan budidaya laut. Pengumpulan kualitas air (suhu, pH, salinitas, kecerahan dan oksigen terlarut) dilakukan pada 21 titik sampling (Gambar 1), dimana penentuan titik sampling dilakukan secara acak, sesuai dengan kebutuhan dan penyebaran yang dianggap mewakili daerah penelitian secara keseluruhan (Morain, 1999).Untuk data klorofil-a diperoleh dengan akuisisi citra Aqua MODISdan acuan Peta Indonesia digital dari Badan Informasi Geospasial, selanjtnya dilakukan koreksi geometrik serta koreksi atmosferik menggunakan algoritma tertentu Xiao et al (2004) dalam Semedi dan Safitri (2015). Nilai rataan konsentrasi klorofil-a kemudian dilayout menjadi peta sebaran klorofila menggunakan ArcGIS.

Pengukuran kondisi oseanografi meliputi kecepatan arus dan kedalaman laut/batimetri. Data pola arus diperoleh dengan pemodelan hidrodinamika ditempuh dengan pendekatan numeric finite volume (Mustikasari, 2015). Batimetri diinterpolasi terhadap grid yang sudah dibuat.Data batimetri merupakan kontur dari kedalaman perairan, diperoleh dari Peta Lembar Indonesia, kemudian dikonversi dalam bentuk format ArGIS. 


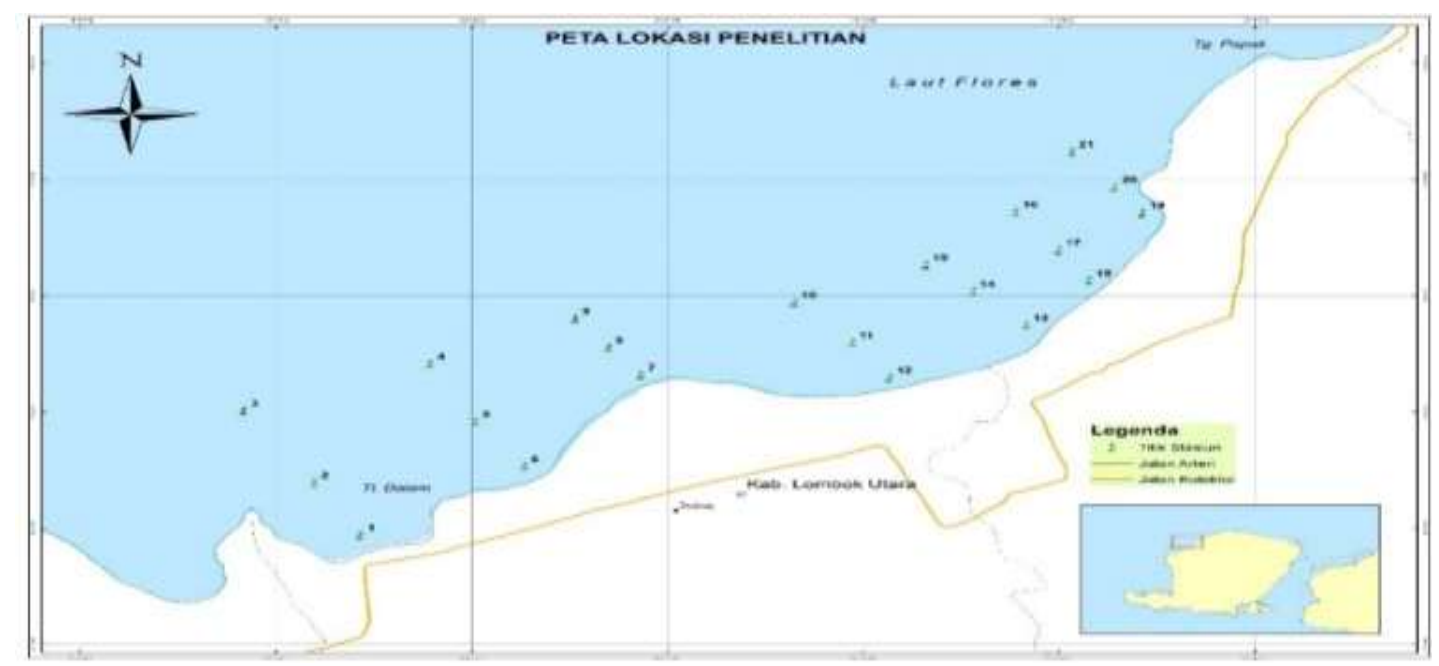

Gambar 1. Lokasi Penelitian dan Titik Pengukuran Kualitas Air

Identifikasi lokasi perairan untuk budidaya laut menuntut penerapan beberapa kriteria. Penerapan kriteria sangat membantu dalam mengidentifikasi dan memilihlokasi budidaya secara obyektif, dimana secara mendasar terdiri dari atas kelompok kriteria kesesuaian kualitas air dan oseanografi. Metode ini sering digunakan didalam proses perencanaan yang umumnya selalu berhadapan dengan variable/parameter yang berdimensi kualitatif.Analisis data untuk mengetahui kesesuaian lokasi pengembangan budidaya laut, meliputi 3 tahapan yaitu penyusunan matriks kesesuaian, pembobotan dan pengharkatan, penentuan kelas kesesuaian dan analisisspasial dengan sistem informasi geografis (SIG). kultivan yaitu rumput laut, ikan kerapu dengan sistem keramba jaring apung dan tiram mutiara (pearls). Pemilihan tersebut didasari kepada potensi ke tiga jenis kultivan, yang dianggap oleh peneliti sebagai komoditi yang dapat dikembangkan dan telah dibudidayakan pada beberapa lokasi di KLU. Penyusunan matriks kesesuaian dilakukan dengan menggunakan kriteria-kriteria kesesuaian lokasi budidaya laut. Kriteria kesesuaian disusun berdasarkan parameter biofisik yang relevan dengan kegiatan budidaya, dan dibuat dengan mengacu pada matriks kriteria kesesuaian dari berbagai studi pustaka seperti FAO (1989); Chou dan Lee (1997), Szuster dan Albasri (2010), dan Amri et al. (2010).

Pengembangan budidaya laut yang direncanakan terdiri atas tiga 


\section{Hasil dan Pembahasan}

\section{Keadaan Umum Lokasi}

KLU merupakan kabupaten pesisir, dengan wilayah perairan laut secara geografi terletak di Selat Lombok dan Laut Flores seluas $503,24 \mathrm{~km}^{2}$ atau sekitar $38,33 \%$ total wilayah KLU dan panjang garis pantai sekitar $125 \mathrm{~km}$. Terdapat 3 buah gugusan pulau yang terkenal dengan sebutan Gili Matra (Meno, Trawangan dan Air) yang merupakan kawasan wisata bahari yang sangat terkenal sampai mancanegara sebagai kawasan tujuan wisata yang indah dan mempesona.Selain dimanfaatkan sebagai Kawasan Wisata Perairan (TWP) Gili Matra seluas 29,54 km², potensi sumberdaya pesisir dan laut KLU sebagian lainnya dimanfaatkan sebagai kawasan perikanan budidaya dan perikanan tangkap (DPPKKP KLU, 2010).Kegiatan budidaya laut di perairan KLU sudah berlangsung dan terbatas pada beberapa sistem dan komoditas budidaya. Sistem budidaya yang digunakan adalah jaring apung dan rakit, sedangkan komoditas yang diusahakan mencakup ikan kerapu cantang macan (Epinephelus sp), ikan bawal bintang (Trachnotus carolinus), rumput laut (Euchema cottonii) dan kerang mutiara (Pinctada maxima).

\section{Kondisi Oseanografi}

Tipe pasang surut perairan KLU sangat mirip dengan tipe pasut Lautan Hindia, yaitu pasut campuran dengan dominasi ganda (mixed semi diurnal). Data real-time pasang surut di-update melalui Www.iocsealevelmonitoring.org dalam dua bulan terakhir (1 September, jam 00:00 WITA) hingga 1 Nopember, jam 00:00 WITA) 2016, memperlihatkan bahwa perbedaan rata-rata air pasang tertinggidan air surut terendah adalah 3,274 $\mathrm{m}$ dan 3,205 m (Gambar 2). Dengan demikian, perbedaan pasang surut tersebut relatif layak untuk pengembangan budidaya laut. 


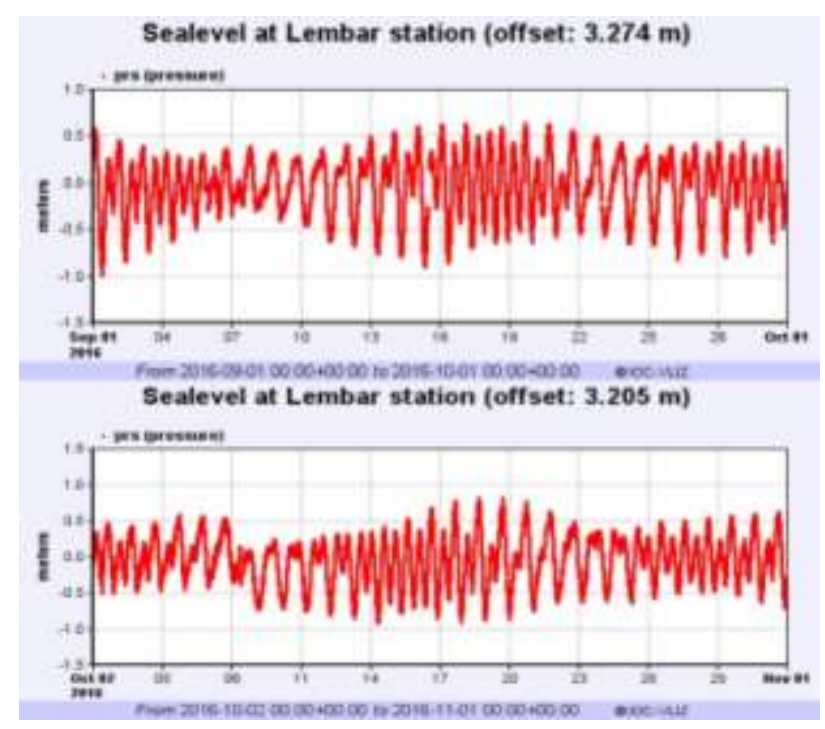

Gambar 2. Tinggi Pasang Surut di KLU pada Bulan Oktober - Nopember 2016

(Sumber : http://www.ioc-sealevelmonitoring.org)

Hasil simulasi pola arus di perairan KLU dengan pemodelan hidrodinamika dengan metode pendekatan numeric finite volume, menunjukkan bahwa pola arus pada bulan Nopember 2016 mengarah ke selatan, kemudian sebelum mencapai daerah pantai KLU berbelok arah ke arah barat, dengan kecepatan sekitar 5 $\mathrm{cm} /$ detik. Kecepatan arus tersebut tergolong lemah. Kecepatan arus air laut sebesar 20-40 $\mathrm{cm} /$ detik merupakan kecepatan optimal yang bisa menghasilkan sirkulasi air yang baik. Sirkulasi air ini berkaitan dengan pasokan oksigen ke dalam sistem dan pembuangan amonia ke luar sistem budidaya. Kecepatan arus air laut kurang dari $20 \mathrm{~cm} /$ detik menghasilkan sirkulasi air yang kurang optimal, sedangkan kecepatan arus melebihi $40 \mathrm{~cm} /$ detik terlalu kuat bagi ikan kultur dan merusak konstruksi sistem budidaya. Hasil simulasi pola arus dalam bentuk peta spasial menunjukkan semua lokasi penelitian termasuk dalam kelas sangat sesuai untuk dikembangkan budidaya laut (Gambar3a) .

Perairan laut KLU memiliki dasar perairan yang sangat terjal, hanya beberapa puluh meter dari bibir pantai kedalaman dapat mencapai 10 m. Sehubungan dengan tujuan penelitian mengidentikasi lokasi perairan untuk budidaya laut, maka areal pengamatan dibatasi pada kedalaman laut sampai $40 \mathrm{~m}$. 
Kedalaman perairan berperan penting terhadap kehidupan biota pada ekosistem tersebut. Semakin dalam perairan maka terdapat zona-zona yang masing-masing memiliki kekhasan tertentu, seperti suhu, kelarutan gas-gas dalam air, kecepatan arus, penetrasi cahaya matahari dan tekanan hidrostatik.Untuk kepentingan budidaya laut, perairan yang terlalu dangkal $(<4 \mathrm{~m})$, tidak sesuai dalam budidaya ikan khusunya ikan kerapu karena dapat menimbulkan beberapa

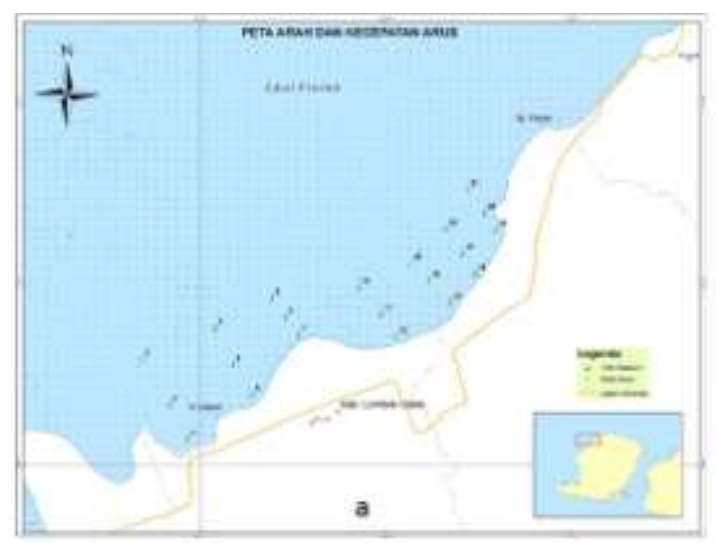

resiko seperti terganggunya kualitas air. Untuk perairan yang dalam ( $>25$ $\mathrm{m})$, kurang efektif untuk budidaya ikan karena dapat mengalami ancaman dari ikan-ikan buas dari laut dalam, disamping itu laut yang dalam tidak lepas dari interaksi ombak dan gelombang. Hasil transformasi peta batimetri dalam bentuk peta spasial menunjukkan semua lokasi penelitian termasuk dalam kelas tidak sampai sangat sesuai untuk dikembangkan budidaya laut (Gambar 3 b) .

Gambar 3. Pola Arus dan Batimetri di Perairan KLU

\section{Kualitas Perairan}

Data kondisi derajat keasaman (pH) hasil pengukuran lapangan memberikan gambaran bahwa kondisi $\mathrm{pH}$ di perairan KLU merupakan perairan yang cenderung basa dengan kisaran $\mathrm{pH}$ antara 8,0 - 8,4. Menurut FAO (1989) perairan dengan $\mathrm{pH}$ netral sampai sedikit basa merupakan perairan dengan kondisi yang ideal pengembangan budidaya laut dengan berbagai komoditas. Toleransi untuk kehidupan ikan terhadap $\mathrm{pH}$ bergantung kepada banyak faktor meliputi suhu, konsentrasi oksigen terlarut, adanya variasi bermcammacam anion dan kation, jenis dan daur hidup biota. Hasil pengukuran $\mathrm{pH}$ dalam bentuk peta spasial menunjukkan semua lokasi penelitian termasuk dalam kelas sangat sesuai 
untuk dikembangkan budidaya laut (Gambar 4a).

Data kondisi derajat keasaman $(\mathrm{pH})$ hasil pengukuran lapangan memberikan gambaran bahwa kondisi pH di perairan KLU dengan kisaran salinitas 27 - 33 ppt, kisaran ini masih baik untuk kegiatan budidaya baik ikan, rumput laut maupun kerang karena salinitas optimal untuk budidaya ketiga komoditas tersebut berada pada kisaran 27 - 35 ppt. Khusus untuk budidaya ikan, nilai salinitas yang dibutuhkan sesuai dengan jenis ikan yang akan dibudidaya. Hal ini dikarenakan ikan tertentu membutuh salinitas tertentu pula. Ikan memiliki toleransi terhadap perubahan salinitas, beberapa jenis ikan memiliki nilai salinitas membutuhkan nilai berbeda. Kerapu secara umum memiliki salinitas optimum pada kisaran 27 - 34 ppt (Affan, 2011). Hasil pengukuran salinitas dalam bentuk peta spasial menunjukkan semua lokasi penelitian termasuk dalam kelas sangat sesuai untuk dikembangkan budidaya laut (Gambar

4b)
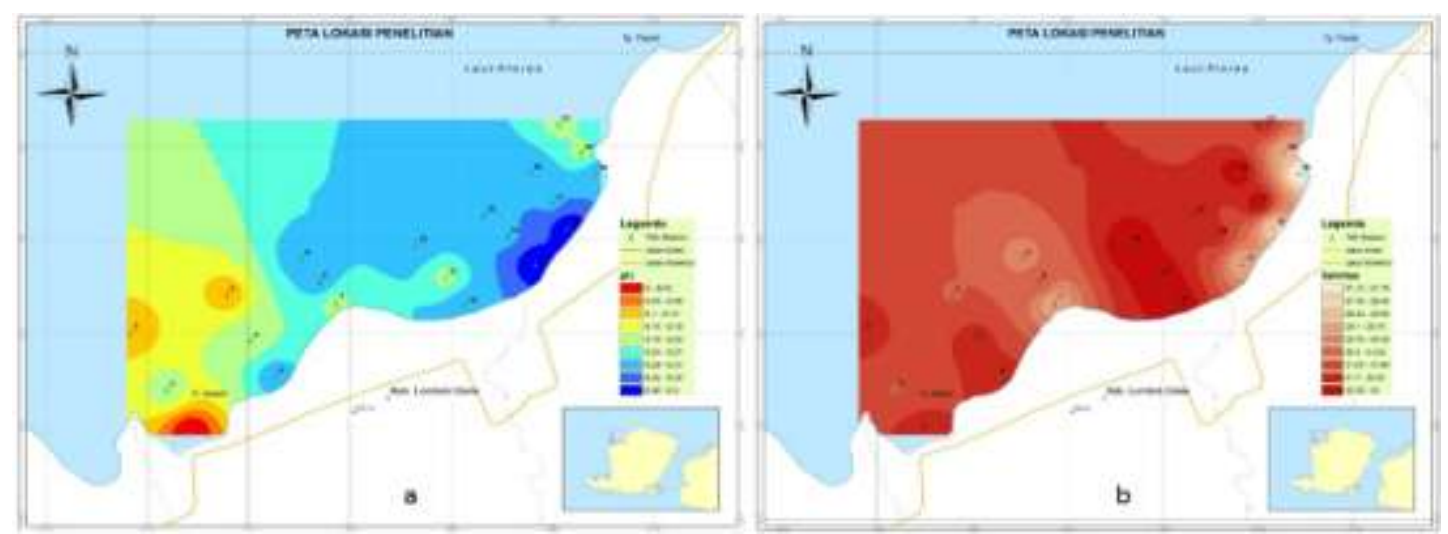

Gambar 4. Kondisi pH dan Salinitas di Perairan KLU

Data kondisi kecerahan hasil pengukuran lapangan memberikan gambaran bahwa kondisi $\mathrm{pH}$ di perairan KLU memiliki kisaran salinitas $1,0-7,5$ m. Kecerahan menunjukkan kemampuan penetrasi cahaya kedalam perairan. Tingkat penetrasi cahaya sangat dipengaruhi oleh partikel yang tersuspensi dan terlarut dalam air sehingga mengurangi laju fotosintesis. Pengukuran kecerahan salah satunya 
dapat dilakukan dengan sechi disk dengan satuan meter atau persentase. Tingkat kecerahan yang terukur sangat relatif terhadap kedalaman perairan. Hasil perhitungan persentase tingkat kecerahan di kawasan ini berkisar antara $60-100 \%$ Menurut Kepmenneg-KLH dalam Affan (2011) kecerahan untuk kegiatan budidaya perikanan sebaiknya lebih dari $3 \mathrm{~m}$. Hasil pengukuran kecerahan dalam bentuk peta spasial menunjukkan semua lokasi penelitian termasuk kelas sesuai dan sangat sesuai untuk dikembangkan budidaya laut (Gambar 5a).

Data kondisi oksigen terlarut atau dissolved oxygen (DO) hasil pengukuran lapangan memberikan gambaran bahwa di perairan KLU memiliki kisaran oksigen terlarut berkisar 6,3 - 12,6 ppm. Oksigen terlarut merupakan parameter yang paling kritis di dalam budidaya ikan dibandingkan rumput laut dan kerang mutiara. Oksigen berasal dari proses difusi udara dan fotosintesis, serta dipengaruhi suhu, salinitas dan tekanan udara. Peningkatan suhu, salinitas dan tekanan menyebabkan penurunan oksigen, begitu juga sebaliknya. Mayunar et al. (1995) menyebutkan jika untuk sekedar hidup diperlukan oksigen $1 \mathrm{ppm}$, namun untuk dapat tumbuh dan berkembang minimal 3 ppm. Untuk kepentingan budidaya ikan, oksigen terlarut yang optimal berkisar 5 - 8 ppm. Hasil pengukuran oksigen terlarut dalam bentuk peta spasial menunjukkan semua lokasi penelitian termasuk kelas sangat sesuai untuk dikembangkan budidaya laut (Gambar 5b).

Data kondisi suhu perairan hasil pengukuran lapangan memberikan gambaran bahwa di perairan KLU memiliki kisaran suhu berkisar 30,4 $32,4{ }^{\circ} \mathrm{C}$. Suhu pada ekosistem perairan berfluktuasi baik harian maupun tahunan, terutama mengikuti pola temperatur udara lingkungan sekitarnya, intensitas cahaya matahari, letak geografis, penaungan dan kondisi internal perairan itu sendiri seperti kekeruhan, kedalaman, kecepatan arus dan timbunan bahan organik di dasar perairan. Suhu memiliki peran yang sangat penting terhadap kehidupan di dalam air. Kelarutan berbagai jenis gas di dalam air serta semua aktivitas biologis di dalam perairan sangatdipengaruhi oleh suhu.Kisaran suhu air yang sangat diperlukan agar pertumbuhan ikan-ikan pada perairan 
tropis dapat berlangsung berkisar antara $25^{\circ} \mathrm{C}-32^{\circ} \mathrm{C}$ (Mayunar et al. (1995). Kisaran suhu tersebut biasanya berlaku di Indonesia sebagai salah satu negara tropis sehingga sangat menguntungkan untuk melakukan kegiatan budi daya ikan.Hasil pengukuran suhu dalam bentuk peta spasial menunjukkan semua lokasi penelitian termasuk kelas sangat sesuai untuk dikembangkan budidaya laut

(Gambar

6a).

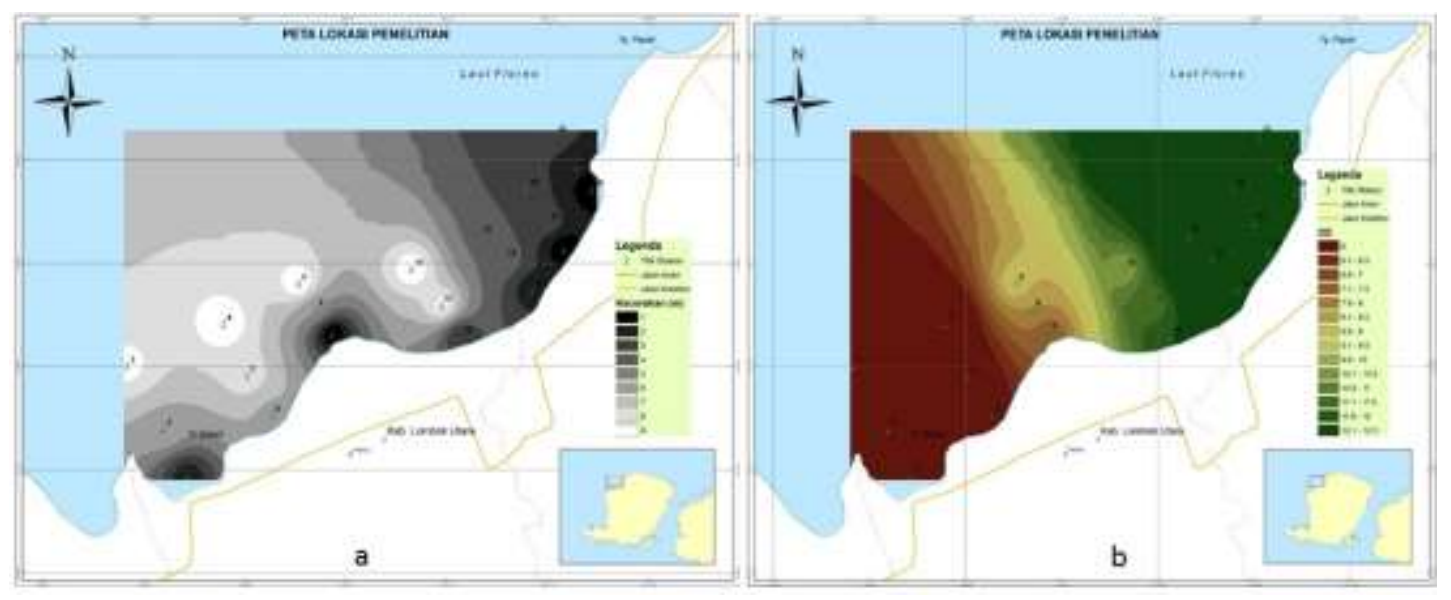

Gambar 5. Kondisi Kecerahan dan Oksigen Terlarut di Perairan KLU

Hasil pengolahan data klorofil-a di perairan KLU dari citra Aqua MODIS menunjukkan bahwa klorofila berkisar antara $<0,27->1,85$. Klorofil lebih dikenal dengan zat hijau daun merupakan pigmen yang terdapat pada organisme produsen yang berfungsi sebagai pengubah karbondioksida menjadi karbohidrat, melalui proses fotosintesa. Klorofil-a merupakan salah satu parameter yang sangat menentukan produktivitas primer di laut. Sebaran dan tinggi rendahnya konsentrasi klorofil-a sangat terkait dengan kondisi oseanografis suatu perairan. Beberapa parameter fisik-kimia yang mengontrol dan mempengaruhi sebaran klorofil-a, adalah intensitas cahaya, nutrien (terutama nitrat, fosfat dan silikat). Perbedaan parameter fisika-kimia tersebut secara langsung merupakan penyebab bervariasinya produktivitas primer di beberapa tempat di laut. Hasil pengolahan klorofil-a dalam bentuk peta spasial menunjukkan semua lokasi penelitian termasuk kelas sangat sesuai untuk dikembangkan budidaya laut (Gambar 6b). 


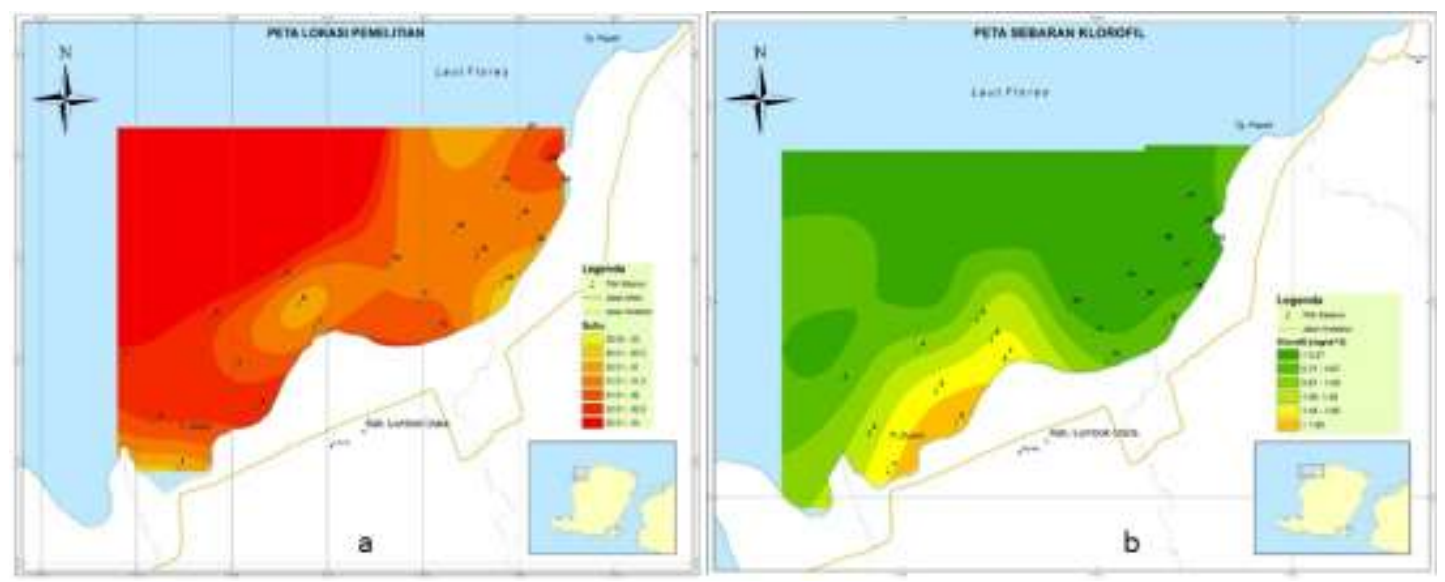

Gambar 6. Kondisi Suhu dan Klorofil-a di Perairan KLU

\section{Kesimpulan}

Berdasarkan hasil dan pembahasan penelitian ini, maka dapat disimpulkan dan direkomendasikan sebagai berikut : (1) identifikasi lokasi perairan berdasarkan aspek oseanografi dan kualitas perairan menunjukkan bahwa kawasan perairan Kabupaten Lombok Utara terutama di Kecamatan Tanjung dan Gangga sangat sesuai untuk pengembangan budidaya laut, (2) pengembangan budidaya laut dapat dilakukan di perairan Kabupaten Lombok Utara, khususnya komoditas yang memiliki peluang ekspor tinggi seperti kerapu, rumput laut dan kerang mutiara, (3) Pengembangan budidaya laut di Kabupaten Lombok Utara perlu mempertimbangkan pemanfaatan lain baik untuk kegiatan perikanan tangkap, ekowisata maupun untuk kawasan konservasi dan (4) pengembangan usaha budidaya laut harus menganut prinsip berkelanjutan, selain memberikan dampak positif terhadap terciptanya lapangan kerja, peningkatan pendapatan dan kesejahteraan juga diharapkan dapat mengurangi tekanan terhadap sumberdaya perikanan laut yang pemanfaatannya secara berlebih.

\section{Daftar Pustaka}

Affan, J.M. 2011. Seleksi lokasi pengembangan budidaya dalam keramba jaring apung (KJA) berdasarkan faktor lingkungan dan kualitas air di perairan pantai timur Kabupaten Bangka Tengah. J. Sains MIPA. Vol 17 (3) : 99-106

Amri, S.N., M. Saenong dan R. Effendi. 2010. Kesesuaian lahan budidaya keramba jaring apung (KJA) ikan kerapu di kawasan perairan Pulau Salemo Kabupaten Pangkep berdasarkan 
analisis sistem informasi geografos. J. Segara,. 6 (1) : 2438

Chou, R and H.B. Lee. 1997. Commercial marine fish farming in Singapure. Aquac. Res 28:767-776.

Effendi, I. 2004. Pengantar Akuakultur. Penebar Swadaya. Jakarta.

FAO. 1989. Food and Agricultural Organization. Site selection criteria for marine finfish netcage culture in Asia. Rome FAO. P 16

Idris, I., S.P. Ginting dan Budiman. 2007. Membangunkan Raksasa Ekonomi: Sebuah Kajian Terhadap Perundang-undangan Pengelolaan Wilayah Pesisir dan Pulau-pulau Kecil. Penerbit Buku Ilmiah Populer. 296 hal.

Ismail, W., P.T. Imanto, B. Priono dan Lamidi. 1996. Pemilihan lokasi ideal bagi penempatan keramba jaring apung reservat di Perairan Kepulauan Riau, Lombok dan Sumbawa. Jurnal Penelitian Perikanan Indonesia Vol. II No. 4, Edisi Akuakultur. BRKP-DKP. Jakarta

Landau, M. 1992. Aquaculture Vol 1. Ellis Horwood, New York. 528 p.

Mayunar, R. Purba dan P.T. Imanto. 1995. Pemilihan lokasi budidaya ikan laut. Prosiding Temu Usaha Pemasyarakatan Teknologi Keramba Jaring Apung bagi Budidaya Laut.
Puslitbang Perikanan. Balitbang Pertanian: 179 - 189.

Morain, S., 1999. GIS Solution in Natural Resource Management: Balancing the echnical-Political Equation. OnWord Press. USA. $361 \mathrm{pp}$.

Radiarta, I.N., A. Saputra, B. Priono. 2005. Identifikasi kelayakan lahan budidaya ikan dalam keramba jaring apung dengan apikasi sistem informasi geografis di Teluk Pangpang, Jawa Timur. Jurnal Penelitian Perikanan Indonesia, 11(5):1-13.

Semedi, B dan N.M. Safitri. 2015. Estimasi distribusi klorofil-a di perairan Selat Madura menggunakan data citra satelit modis dan pengukuran in situ pada musim timur. Res. J. Life Sci., 2 (1) : 40-49.

Syukur, A., Syahrudi, AR., Mahrus. 2016. The potential assessment environment friendly aquaculture of small-scale fishermen as a conservation strategy seagrass beds in coastal areas of Tanjung Luar East Lombok, Indonesia. International Journal of Fisheries and Aquatic Studies, 4 (2): $22-27$

Szuster, W.B. And H. Albasri. 2010. Site selection for grouper mariculture in Indonesia. Int. J.Fish. Aquac, 2(3): 87-92.

Utoyo, S., R.N. Ansari dan Sutriyani. 2000. Studi kelayakan sumberdaya lahan budidaya laut di Pulau-Pulau Sembilan, Kabupaten Sinjai Sulawesi Selatan. Balitanta Maros. 
